\title{
Prevalence and Correlates of Disordered Eating Behaviors Among Young Adults with Overweight or Obesity
}

\author{
Jason M. Nagata, MD, MSc' , Andrea K. Garber, PhD, RD' , Jennifer L. Tabler, $P h D^{2}$, \\ Stuart B. Murray, $P h D^{3}$, and Kirsten Bibbins-Domingo, MD, $P h D, M A S^{4,5}$
}

'Division of Adolescent and Young Adult Medicine, , University of California, San Francisco, CA, USA; ${ }^{2}$ Department of Sociology and Anthropology, University of Texas Rio Grande Valley, Edinburg, TX, USA; ${ }^{3}$ Department of Psychiatry, University of Californias, San Francisco, CA, USA; ${ }^{4}$ Department of Epidemiology and Biostatistics, University of California, San Francisco, CA, USA; ${ }^{5}$ Department of Medicine, University of California, San Francisco, CA, USA.

BACKGROUND: Clinical and community samples indicate that eating disorders (EDs) and disordered eating behaviors (DEBs) may co-occur among adolescents and young adults at a weight status classified as overweight or obese.

OBJECTIVE: To determine the prevalence of EDs and DEBs among young adults at a weight status classified as overweight or obese using a nationally representative sample and to characterize differences in prevalence by sex, race/ethnicity, sexual orientation, and socioeconomic status.

DESIGN: Cross-sectional nationally representative data collected from Wave III of the National Longitudinal Study of Adolescent to Adult Health (Add Health).

PARTICIPANTS: Young adults ages 18-24 years old.

MAIN MEASURES: ED diagnosis and DEBs (self-reported binge eating or unhealthy weight control behaviors including vomiting, fasting/skipping meals, or laxative/ diuretic use to lose weight). Covariates: age, sex, race/ethnicity, sexual orientation, weight status, and education.

KEY RESULTS: Of the 14,322 young adults in the sample, $48.6 \%$ were at a weight status classified as overweight or obese. Compared to young adults at a weight status classified as underweight or normal weight, those at a weight status classified as overweight or obese reported a higher rate of DEBs (29.3 vs $15.8 \%$ in females, 15.4 vs $7.5 \%$ in males). Logistic regression analyses demonstrated that odds of engaging in DEBs were 2.32 (95\% confidence interval 2.05-2.61) times higher for females compared to males; 1.66 (1.23-2.24) times higher for Asian/ Pacific Islander compared to White; 1.62 (1.16-2.26) times higher for homosexual or bisexual compared to heterosexual; 1.26 (1.09-1.44) times higher for high school or less versus more than high school education; and 2.45 (2.16-2.79) times higher for obesity compared to normal weight, adjusting for all covariates.

CONCLUSIONS: The high prevalence of DEBs particularly in young adults at a weight status classified as overweight or obese underscores the need for screening, referrals, and tailored interventions for DEBs in this population.

Received September 11, 2017

Revised February 26, 2018

Accepted April 12, 2018

Published online June 11, 2018
KEYWORDS: obesity; eating disorders; anorexia nervosa; bulimia nervosa; binge eating; weight control behaviors; young adult.

J Gen Intern Med 33(8):1337-43

DOI: $10.1007 / \mathrm{s} 11606-018-4465-z$

(c) Society of General Internal Medicine 2018

\section{INTRODUCTION}

Obesity, eating disorders (EDs), and disordered eating behaviors (DEBs) are highly prevalent in adolescents and young adults and represent significant public health challenges due to their potentially serious medical and psychosocial consequences. ${ }^{1,2}$ By national estimates, $34.5 \%$ of adolescents and $60.3 \%$ of adults ages $20-39$ are at a weight status classified as overweight or obese. ${ }^{3}$ In comparison, lifetime prevalence estimates for EDs range from 0.6 to $2.0 \%$ for anorexia nervosa, 1.0 to $4.6 \%$ for bulimia nervosa, and 0.6 to $4.5 \%$ for binge eating disorder, with mean and median ages of onset for all three in young adulthood. ${ }^{4}{ }^{5}$ DEBs, including binge eating or unhealthy weight control behaviors such as vomiting, fasting, skipping meals, and laxative/diuretic use to lose weight, constitute some of the core criteria for a Diagnostic and Statistical Manual, 5th Edition (DSM-5), ED diagnosis. ${ }^{6}$ Even in the absence of meeting full DSM-5 criteria, DEBs are of pressing medical concern and are associated with increased risk for eating disorders, ${ }^{7,8}$ depression, ${ }^{9}$ alcohol and tobacco use, ${ }^{10}$ poor nutritional intake and quality, ${ }^{9}$ and significant weight gain over time. ${ }^{11}$

Studies indicate that a large proportion of adolescents and young adults at a weight status classified as overweight/obese engage in DEBs. Perhaps the best estimate of this problem in a community sample comes from Project EAT (Eating Among Teens), a regional cohort of adolescents $(n=2516)$ based in St. Paul, MN. ${ }^{9,}{ }^{12-14}$ In that sample, $40 \%$ of girls and $20 \%$ of boys at a weight status classified as overweight engaged in binge eating or unhealthy weight control behaviors including fasting, eating very little food, using food substitutes, or smoking to lose weight in the past year. ${ }^{14}$ At 10 -year followup, the high prevalence of DEBs remained the same among young adults at a weight status classified as overweight in the Project EAT cohort. ${ }^{12}$ Other than Project EAT, examinations of 
this striking co-occurrence of overweight/obesity and EDs/ DEBs have been mostly limited to single-center, clinical samples. ${ }^{15,}{ }^{16}$ Nationally representative studies of DEBs in young adults have estimated that $19.1 \%$ of young adults engage in dieting ${ }^{17}$ and that the prevalence of diet pill use increases from adolescence to young adulthood while the prevalence of purging remains constant ${ }^{18}$; however, these results were not disaggregated by weight status. Although Project EAT significantly advanced the field based on a Minnesota cohort, the prevalence of DEBs with overweight/obesity has not yet been described with nationally representative data in young adulthood. Young adulthood represents a critical developmental period that is distinct from adolescence and older adulthood. ${ }^{19}$ Young adults have a worse health profile and are less likely to eat breakfast, exercise, and get regular physical and dental checkups than adolescents. ${ }^{19}$

Prior research has demonstrated differential risk for DEBs by demographic and socioeconomic characteristics. Although females are generally thought to have higher risk for DEBs, ${ }^{14}$, ${ }^{20}$ male presentations of DEBs may be under-recognized and be more muscularity driven. ${ }^{21,} 22$ Asian Americans have previously been shown to have more body dissatisfaction and have higher binge eating compared to whites. ${ }^{23,}{ }^{24}$ Sexual minority males ${ }^{25}$ and females ${ }^{26}$ have been shown to have higher risk for DEBs compared to their heterosexual counterparts. Low educational attainment has been shown to be associated with DEBs in females. ${ }^{27}$

The present study will build on the prior scientific knowledge from regional studies examining the coexistence of overweight/ obesity and EDs/DEBs in adolescents to a large national sample in young adults, a unique and understudied population. The objective of this study is to determine the prevalence of overweight/obesity with EDs/DEBs using nationally representative data in young adults. A second aim is to characterize differences in prevalence by sex, race/ethnicity, sexual orientation, and socioeconomic status to inform future efforts to target screening and interventions. We hypothesize that females, sexual minorities, Asian/Pacific Islanders, and young adults with lower educational attainment will have higher odds of DEBs.

\section{METHODS}

\section{Study Population}

This study uses data from the National Longitudinal Study of Adolescent to Adult Health (Add Health), a longitudinal cohort study of a nationally representative sample of adolescents in the USA who were followed into adulthood. ${ }^{28}$ Add Health was developed in response to a mandate from the US Congress to study adolescent health, with a focus on health and risk behaviors. The baseline sample was collected in 1994-1995 when subjects were adolescents and used systematic sampling methods and implicit stratification to ensure that the high schools $(n=80)$ and paired middle schools selected were representative of US schools with respect to region of country, urbanicity, size, type, and ethnicity. Students in each school were stratified by grade and sex. About 17 students were randomly chosen from each stratum so that a total of approximately 200 adolescents were selected from each of the 80 pairs of schools to have in-home interviews. For this particular study, we used the nationally representative restricted-use cross-sectional sample from Wave III, which was collected from August 2001 to April 2002 when subjects were young adults. Of the 18,924 adolescents in the nationally representative weighted baseline sample (Wave I), 14,322 (75.7\%) participated in Wave III during young adulthood. Wave III was the only wave that collected detailed information about ED diagnosis and DEBs. The University of North Carolina Institutional Review Board approved all Add Health study procedures, and the University of California, San Francisco Institutional Review Board deemed this specific project exempt. Further details about the study design can be found elsewhere. ${ }^{28}$

\section{Procedures}

In Wave III, an interviewer traveled to the home or another suitable location for the research subject. Written informed consent was obtained from the subject. Interviews lasted approximately $90 \mathrm{~min}$. Computer-assisted self-interview technology was used by participants to answer potentially sensitive questions. Immediately following the interview, interviewers recorded physical measurements such as height and weight.

\section{Measures}

Dependent Variables. Eating Disorder Diagnosis. A selfidentified eating disorder diagnosis was determined with an affirmative response to the question, "have you ever been told by a doctor that you have an eating disorder, such as anorexia nervosa or bulimia?"

Unhealthy Weight Control Behaviors. Individuals were asked, "During the past seven days, which of the following things did you do in order to lose weight or to keep from gaining weight?" Those who had affirmative responses to (1) fasted or skipped meals, (2) made yourself throw up, (3) took weight loss pills, (4) took laxatives, or (5) used diuretics were coded as having unhealthy weight control behaviors. These questions were similar to validated eating behavior measures such as in the Eating Disorder Examination Questionnaire, ${ }^{29}$ except that the time frame was 7 instead of 28 days to be consistent with the 7-day time frame of other validated questions in the Add Health survey on nutrition and physical activity. ${ }^{30}$

Binge Eating Behaviors. Individuals were asked, "In the past seven days, have you eaten so much in a short period that you would have been embarrassed if others had seen you do it?" and "In the past seven days, have you been afraid to start eating because you thought you wouldn't be able to stop or control your eating?" Those who had affirmative responses to either question were coded as having binge eating behaviors. 
Disordered Eating Behaviors. Participants who reported unhealthy weight control behaviors or binge eating behaviors in the past 7 days were considered to have DEBs.

Independent Variables. Age, sex, and race/ethnicity were recorded based on self-report. ${ }^{28}$

Sexual orientation was classified based on an item in Wave III asking participants to choose the description that best fit how participants identified: $100 \%$ heterosexual (straight); mostly heterosexual (straight), but somewhat attracted to people of your own sex; bisexual, that is, attracted to men and women equally; mostly homosexual (gay) but somewhat attracted to people of the opposite sex; or $100 \%$ homosexual (gay). Because of the small percentage of respondents identifying as bisexual, mostly homosexual, or $100 \%$ homosexual, we combined these categories for the purposes of the analysis.

Education was based on self-report and dichotomized into high school or less versus more than high school, similar to other large population-based studies in young adults. $^{31,32}$ Of socioeconomic markers (i.e., education, income, and occupation), education is found to be most robustly associated with a variety of mental and physical health outcomes. For this reason, education is often the standard socioeconomic proxy utilized in epidemiological studies $^{33-35}$ including in young adults ${ }^{31,32}$ and in eating disorders. $^{27,36}$

Body mass index (BMI) was calculated using the standard formula weight (kilograms) divided by height (meters) squared $\left(\mathrm{BMI}=\right.$ weight $/$ height $\left.^{2}\right)$. Weight and height were measured by the interviewer in Wave III.

Weight Status. Young adults were classified as underweight (BMI < 18.5), normal weight $(18.5 \leq \mathrm{BMI}<25)$, overweight $(25 \leq \mathrm{BMI}<30)$, or obese (BMI $\geq 30)$ in accordance with guidelines from the US Centers for Disease Control and Prevention $(\mathrm{CDC}) .^{37}$

\section{Statistical Analysis}

Data analysis was performed in 2017 using STATA 15.0. We used Add Health's pre-constructed sample weights for Wave III to determine estimates for national prevalence. Further details about the Add Health sampling strategy and application of sampling weights are described in detail elsewhere. ${ }^{38,39} \mathrm{We}$ used multiple logistic regression analyses to identify associations with any DEB, unhealthy weight control behaviors, and binge eating as the dependent variables and age, sex, race/ethnicity, sexual orientation, years of schooling, and BMI as the independent variables. We used listwise deletion for missing data in the regression models; missing data were minimal for all variables $(<1.5 \%)$. $P<0.05$ was considered significant.

\section{RESULTS}

Of the 14,322 young adults (ages 18-24) included in Wave III of Add Health, nearly half of subjects were at a weight status classified as overweight $(25.7 \%)$ or obese $(22.9 \%$, Table 1$)$. Young adults at a weight status classified as obese reported the highest rates of DEBs (25.3\%, Fig. 1). In general, a higher proportion of females than males reported an ED diagnosis, unhealthy weight control behaviors, and binge eating behavior. Similarly, young adults at a weight status classified as overweight/obese reported higher rates of unhealthy weight control behaviors and binge eating behaviors but reported lower proportions of ED diagnoses compared to those at a weight status classified as underweight/normal weight (Table 1).

Logistic regression analyses demonstrated that odds of engaging in unhealthy weight control behaviors were 2.45 (95\% confidence interval 2.16-2.79) times higher for obese compared to normal weight and 2.32 (2.05-2.61) times higher for females compared to males in adjusted analyses (Table 2). Asian/Pacific Islander race/ethnicity (OR 1.97 [1.46-2.67]) and identifying as homosexual or bisexual (OR 1.32 [1.091.63]) were associated with greater odds of binge eating behaviors in adjusted analyses (Table 2).

\section{DISCUSSION}

We highlight with a nationally representative sample that over $30 \%$ of female and over $15 \%$ of male young adults at a weight status classified as overweight/obese reported an ED or DEB. Young adults at a weight status classified as overweight/obese reported higher rates of DEBs but lower rates of ED diagnosis compared to young adults at a weight status classified as underweight/normal weight. Particular young adult subpopulations at highest risk for DEBs who might benefit from targeted interventions include females, Asian/Pacific Islanders, sexual minorities, those with less educational attainment, and those with obesity.

The coexistence of overweight/obesity with EDs/DEBs is becoming increasingly recognized. ${ }^{15,16}$ The largest community-based study, the Minnesota-based Project EAT, estimated that $40 \%$ of adolescent girls and $20 \%$ of adolescent boys at a weight status classified as overweight engaged in $\mathrm{DEBs}^{14}$ and this prevalence remained stable at 10-year followup in young adulthood. ${ }^{12}$ Using nationally representative data, our study estimates a slightly lower prevalence (29\% in females and $15 \%$ in males) of DEBs among young adults at a weight status classified as overweight/obese. This difference may be attributed to the fact that Project EAT assessed DEBs in the past year ${ }^{11}$ whereas Add Health assessed DEBs in the past 7 days. The $2.1 \%$ ED prevalence in this national sample is consistent with the lifetime prevalence estimates reported for anorexia nervosa (0.6-2.0\%) and bulimia nervosa (1.0-4.6\%) in other large samples. ${ }^{4,5}$ 
Table 1 Demographic and Health Characteristics of Full Sample and Stratified by Sex and Baseline Weight Status

\begin{tabular}{|c|c|c|c|c|c|c|}
\hline & \multirow{4}{*}{$N^{*}$} & \multirow{3}{*}{$\begin{array}{l}\text { Total } \\
14,322\end{array}$} & \multicolumn{2}{|c|}{$\begin{array}{l}\text { Underweight or normal } \\
\text { weight }\end{array}$} & \multicolumn{2}{|c|}{ Overweight or obese } \\
\hline & & & \multirow{2}{*}{$\frac{\text { Female }}{3176}$} & \multirow{2}{*}{$\begin{array}{l}\text { Male } \\
4007\end{array}$} & \multirow{2}{*}{$\frac{\text { Female }}{3457}$} & \multirow{2}{*}{$\begin{array}{l}\text { Male } \\
3558\end{array}$} \\
\hline & & & & & & \\
\hline & & $\underset{\%^{\dagger}}{\operatorname{Mean}} \pm \mathrm{SE} /$ & $\underset{\%^{\dagger}}{\operatorname{Mean}} \pm \mathrm{SE} /$ & $\underset{\%^{\dagger}}{\operatorname{Mean}} \pm \mathrm{SE} /$ & $\underset{\%^{\dagger}}{\operatorname{Mean}} \pm \mathrm{SE} /$ & $\underset{\%^{\dagger}}{\operatorname{Mean}} \pm \mathrm{SE} /$ \\
\hline \multicolumn{7}{|l|}{ Demographic characteristics } \\
\hline Age, years & 14,322 & $21.82 \pm 0.12$ & $21.60 \pm 0.13$ & $21.69 \pm 0.13$ & $21.87 \pm 0.12$ & $22.13 \pm 0.12$ \\
\hline Race/ethnicity & 14,312 & & & & & \\
\hline White (non-Hispanic) & & $67.9 \%$ & $73.5 \%$ & $67.7 \%$ & $62.5 \%$ & $67.1 \%$ \\
\hline Black/African American (non-Hispanic) & & $15.5 \%$ & $11.5 \%$ & $15.2 \%$ & $21.2 \%$ & $15.2 \%$ \\
\hline Hispanic/Latino & & $11.8 \%$ & $9.6 \%$ & $11.7 \%$ & $13.5 \%$ & $12.7 \%$ \\
\hline Asian/Pacific Islander (non-Hispanic) & & $3.4 \%$ & $4.4 \%$ & $4.3 \%$ & $1.7 \%$ & $3.1 \%$ \\
\hline American Indian/Native American & & $0.5 \%$ & $0.2 \%$ & $0.3 \%$ & $0.7 \%$ & $0.9 \%$ \\
\hline Other & & $0.7 \%$ & $0.8 \%$ & $0.8 \%$ & $0.4 \%$ & $0.1 \%$ \\
\hline Sexual orientation & 14,121 & & & & & \\
\hline Heterosexual & & $90.1 \%$ & $84.9 \%$ & $93.3 \%$ & $86.5 \%$ & $95.6 \%$ \\
\hline Mostly heterosexual & & $6.9 \%$ & $11.6 \%$ & $3.9 \%$ & $9.4 \%$ & $2.5 \%$ \\
\hline Homosexual or bisexual & & $3.1 \%$ & $3.5 \%$ & $2.9 \%$ & $4.1 \%$ & $2.0 \%$ \\
\hline Educational attainment & 14,309 & & & & & \\
\hline High school or less & & $47.7 \%$ & $37.1 \%$ & $48.2 \%$ & $51.0 \%$ & $51.6 \%$ \\
\hline More than high school & & $52.3 \%$ & $62.9 \%$ & $51.8 \%$ & $49.0 \%$ & $48.4 \%$ \\
\hline Health characteristics & & & & & & \\
\hline Body mass index (BMI), $\mathrm{kg} / \mathrm{m}^{2}$ & 14,198 & $26.40 \pm 0.13$ & $21.55 \pm 0.04$ & $22.00 \pm 0.05$ & $32.21 \pm 0.17$ & $30.52 \pm 0.15$ \\
\hline Weight status & 14,198 & & & & & \\
\hline Underweight (BMI < 18.5) & & $3.4 \%$ & $8.2 \%$ & $4.9 \%$ & $\mathrm{~N} / \mathrm{A}$ & $\mathrm{N} / \mathrm{A}$ \\
\hline Normal weight $(18.5 \leq \mathrm{BMI}<25)$ & & $48.0 \%$ & $91.8 \%$ & $95.1 \%$ & $\mathrm{~N} / \mathrm{A}$ & $\mathrm{N} / \mathrm{A}$ \\
\hline Overweight $(25 \leq \mathrm{BMI}<30)$ & & $25.7 \%$ & $\mathrm{~N} / \mathrm{A}$ & $\mathrm{N} / \mathrm{A}$ & $46.5 \%$ & $58.4 \%$ \\
\hline Obese $(\mathrm{BMI} \geq 3 \overline{0})$ & & $22.9 \%$ & $\mathrm{~N} / \mathrm{A}$ & $\mathrm{N} / \mathrm{A}$ & $53.5 \%$ & $41.6 \%$ \\
\hline Diagnosed with eating disorder (ED) & 14,305 & $2.1 \%$ & $4.9 \%$ & $0.6 \%$ & $2.6 \%$ & $0.3 \%$ \\
\hline Unhealthy weight control behaviors (UWCB) & 14,322 & $11.0 \%$ & $9.6 \%$ & $2.2 \%$ & $22.7 \%$ & $10.3 \%$ \\
\hline Binge eating behaviors & 14,305 & $7.3 \%$ & $7.9 \%$ & $5.3 \%$ & $9.8 \%$ & $6.4 \%$ \\
\hline $\begin{array}{l}\text { Disordered eating behavior (DEB = UWCB or } \\
\text { binge eating) }\end{array}$ & 14,322 & $16.7 \%$ & $15.8 \%$ & $7.5 \%$ & $29.3 \%$ & $15.4 \%$ \\
\hline Any ED or DEB & 14,322 & $18.1 \%$ & $19.2 \%$ & $8.0 \%$ & $30.4 \%$ & $15.6 \%$ \\
\hline
\end{tabular}

N/A not applicable

*Group $n$ may not sum to total $N$ because of missing data

${ }^{\dagger}$ All means and percentages are calculated with weighted data to reflect the representative proportion in the target US population

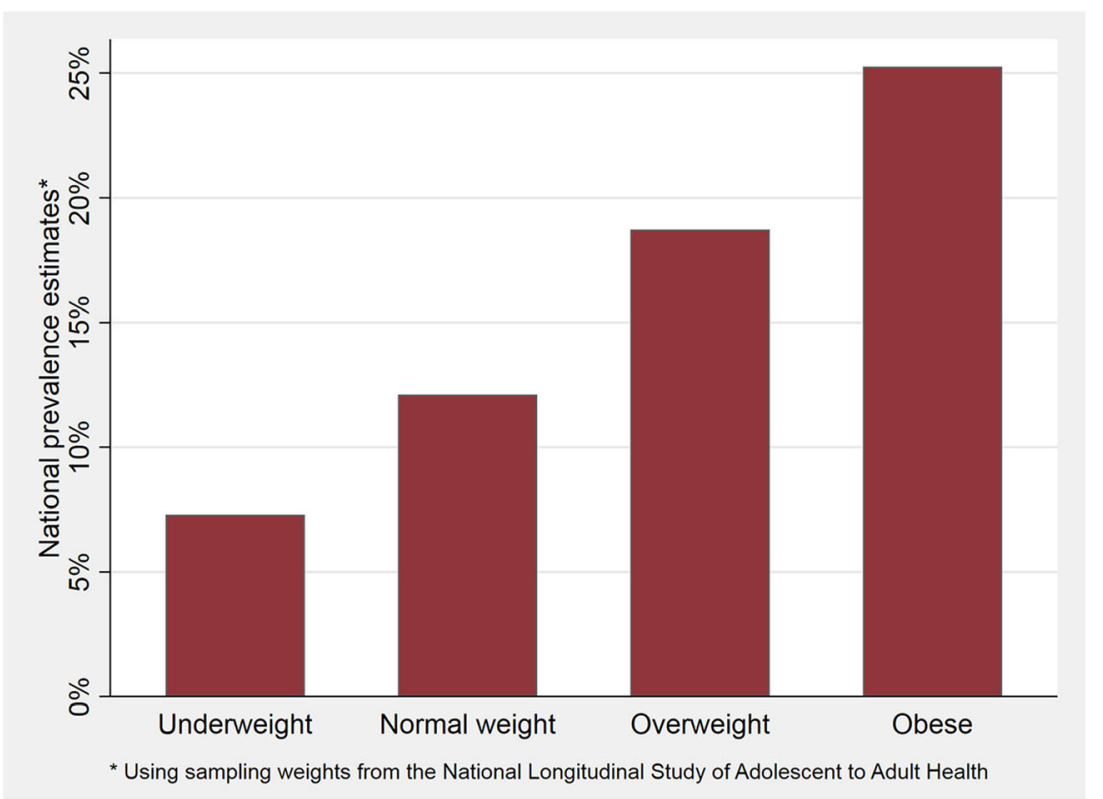

Fig. 1 Prevalence of disordered eating behaviors among young adults in the National Longitudinal Study of Adolescent to Adult Health, by weight status. 
Table 2 Logistic Regression Analysis for Sociodemographic Variables Associated with Odds of Unhealthy Weight Control Behavior, Binge Eating Behavior, or Any Disordered Eating Behavior

\begin{tabular}{|c|c|c|c|c|c|c|}
\hline & $\begin{array}{l}\text { Unhealthy weight control } \\
\text { behavior (UWCB) }\end{array}$ & $P$ & $\begin{array}{l}\text { Binge eating } \\
\text { behavior }\end{array}$ & $P$ & $\begin{array}{l}\text { Any disordered eating } \\
\text { behavior }(\mathrm{DEB}=\mathrm{UWCB} \\
\text { or binge) }\end{array}$ & $P$ \\
\hline & Odds ratio $(95 \% \mathrm{CI})^{*}$ & & Odds ratio $(95 \% \mathrm{CI})^{*}$ & & Odds ratio $(95 \% \mathrm{CI})^{*}$ & \\
\hline Age & $0.97(0.93-1.01)$ & 0.169 & $0.99(0.95-1.03)$ & 0.657 & $0.98(0.95-1.01)$ & 0.188 \\
\hline \multicolumn{7}{|c|}{ 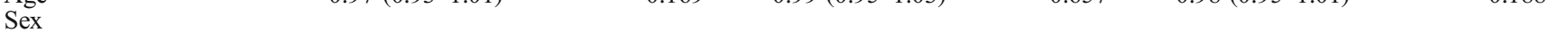 } \\
\hline Male & 1.00 (referent) & & 1.00 (referent) & & 1.00 (referent) & \\
\hline Female & $2.93(2.51-3.42)$ & $<0.001$ & $1.62(1.38-1.92)$ & $<0.001$ & $2.32(2.05-2.61)$ & $<0.001$ \\
\hline \multicolumn{7}{|l|}{ Race/ethnicity } \\
\hline White (non-Hispanic) & 1.00 (referent) & & 1.00 (referent) & & 1.00 (referent) & \\
\hline $\begin{array}{l}\text { Black/African American } \\
\text { (non-Hispanic) }\end{array}$ & $1.01(0.83-1.23)$ & 0.915 & $1.12(0.88-1.42)$ & 0.355 & $1.04(0.86-1.26)$ & 0.665 \\
\hline Hispanic/Latino & $1.19(0.95-1.49)$ & 0.122 & $1.32(0.98-1.78)$ & 0.070 & $1.25(1.00-1.57)$ & 0.047 \\
\hline $\begin{array}{l}\text { Asian/Pacific Islander } \\
\text { (non-Hispanic) }\end{array}$ & $1.25(0.79-1.96)$ & 0.339 & $1.97(1.46-2.67)$ & $<0.001$ & $1.66(1.23-2.24)$ & 0.001 \\
\hline $\begin{array}{l}\text { American Indian/Native } \\
\text { American }\end{array}$ & $0.96(0.51-1.82)$ & 0.339 & $0.66(0.28-1.57)$ & 0.341 & $0.87(0.50-1.49)$ & 0.600 \\
\hline Other & $0.68(0.24-1.94)$ & 0.472 & $1.36(0.57-3.23)$ & 0.485 & $0.89(0.41-1.95)$ & 0.767 \\
\hline \multicolumn{7}{|l|}{ Sexual Orientation } \\
\hline $\begin{array}{l}\text { Heterosexual } \\
\text { Mostly heterosexual }\end{array}$ & 1.00 (referent) & & 1.00 (referent) & & 1.00 (referent) & \\
\hline Homosexual or bisexual & $\begin{array}{l}1.44(1.12-1.03) \\
1.53(1.02-2.29)\end{array}$ & $\begin{array}{l}0.004 \\
0.040\end{array}$ & $\begin{array}{l}1.28(0.96-1.69) \\
1.44(0.98-2.13)\end{array}$ & 0.090 & $\begin{array}{l}1.32(1.01-1.03) \\
162(1.16-2.26)\end{array}$ & $\begin{array}{l}0.010 \\
0.005\end{array}$ \\
\hline High school education or less & $1.11(0.95-1.30)$ & 0.175 & $1.32(1.09-1.63)$ & 0.006 & $1.26(1.09-1.44)$ & 0.002 \\
\hline \multicolumn{7}{|l|}{ Weight status } \\
\hline Normal weight & 1.00 (referent) & & 1.00 (referent) & & 1.00 (referent) & \\
\hline Underweight & $0.50(0.26-0.99)$ & 0.047 & $0.54(0.31-0.95)$ & 0.033 & $0.47(0.28-0.78)$ & 0.003 \\
\hline Overweight & $2.46(2.06-2.93)$ & $<0.001$ & $1.25(1.04-1.49)$ & 0.016 & $1.84(1.62-2.10)$ & $<0.001$ \\
\hline Obese & $3.86(0.02-0.14)$ & $<0.001$ & $1.14(0.91-1.44)$ & 0.259 & $2.45(2.16-2.79)$ & $<0.001$ \\
\hline
\end{tabular}

Italic indicates $P<0.05$

*Adjusted for age, sex, racelethnicity, sexual orientation, education, and weight status

Similar to findings with Project EAT, females in our sample had higher rates of EDs/DEBs than males. ${ }^{14}$ In partially accounting for this, females with body image concerns are often driven towards thinness and losing weight, while males with body image concerns are often driven to gain more muscle. ${ }^{40,}{ }^{41}$ Questions related to vomiting, fasting or skipping meals, diuretics, and laxative use that served as a proxy for unhealthy weight control behaviors represent thinness-oriented goals, which may be more relevant to females. Future research could examine sex differences ${ }^{42-44}$ in compulsive exercise ${ }^{45}$ or androgenic anabolic steroid use, ${ }^{46}$ which may be more prevalent among young adult men than women considered overweight or obese.

We found that Asian/Pacific Islander young adults had higher odds of binge eating compared to white young adults. In one nationally representative study, Asian Americans reported a higher prevalence of binge eating compared to whites; however, they were equally likely to be diagnosed with binge eating disorder and less likely than whites to receive services for eating problems. ${ }^{24}$ The under-diagnosis of binge eating disorder was attributed to the finding that Asian Americans may be less likely to endorse binge eating disorder symptoms related to distress or loss of control. ${ }^{24}$ Future research may further explore EDs/DEBs in Asian American populations and identify specific screening tools to address a potential underdiagnosis of binge eating.

We find that non-exclusively heterosexual young adults are at greater risk for DEBs, confirming findings of prior studies that have shown an increased risk for DEBs among gay and bisexual men ${ }^{25}$ and lesbian and bisexual women ${ }^{26}$ compared to their heterosexual counterparts. We also find that DEBs are associated with lower educational attainment, similar to previous studies in young adults. ${ }^{27}$ Higher BMI was associated with higher odds of unhealthy weight control behaviors. Previous studies in adolescent girls have demonstrated that greater BMI is associated with greater weight concerns. ${ }^{47}$

Although EDs were first recognized and described in the context of undernutrition and low weight, the realization that disordered eating may occur across the weight spectrum including in the context of obesity has led to recent changes in diagnostic criteria. For instance, the Diagnostic and Statistical Manual for Mental Disorders, Fourth Edition (DSM-IV), ${ }^{48}$ previously indicated that the maintenance of body weight less than $85 \%$ of expected body weight was suggested for anorexia nervosa. The DSM-5, published in 2013, eliminated these suggested weight cutoffs and added the diagnosis of atypical anorexia nervosa, when all criteria for anorexia nervosa are met, except despite significant weight loss, the individual's weight is within or above the normal range. ${ }^{6}$ Moreover, the DSM-5 added binge eating disorder as a formal ED diagnosis. ${ }^{6}$ Given the high rates of DEBs in young adults at a weight status classified as overweight/obese, clinicians should consider screening for these behaviors and providing referrals or tailored interventions as appropriate. The potentially high comorbidity of overweight/obesity with EDs/DEBs suggests that interventions may be most effective taking an integrated approach that simultaneously addresses a spectrum of weight- 
related problems. ${ }^{14}$ The American Academy of Pediatrics has recently published guidelines on preventing both obesity and eating disorders in adolescents ${ }^{49}$; however, we are unaware of similar guidelines tailored specifically to young adults.

Our study has several limitations that merit acknowledgement. First, due to the design of the Add Health survey, we were unable to distinguish types of EDs, measure the severity or duration of reported DEBs, or identify if respondents had received treatment for an ED. EDs/DEBs were based on selfreport, a method that is may be subject to reporting bias. In addition, data were collected in 2001-2002 during the era of DSM-IV ${ }^{48}$ ED diagnoses, binge eating disorder was not specifically listed as an ED diagnosis, and the DEB questions alone do not constitute an ED diagnosis. The time frame used for measuring DEBs in Add Health was shorter (past 7 days) than is often asked in other measures of DEBs such as the Eating Disorder Examination Questionnaire (past 28 days) ${ }^{29}$ or in Project EAT (past year), ${ }^{11}{ }^{14}$ which may have underestimated the prevalence of DEBs compared to other studies. The Add Health survey only asked ED diagnosis questions in Wave III, which is why we were only able to analyze the prevalence of EDs/DEBs cross-sectionally in young adulthood and not at other time points. There was the possibility for selection bias given a $75.7 \%$ retention rate in Wave III. However, there was minimal missing data for all included variables $(<1.5 \%)$. Although we controlled for education, there is the possibility of confounding given lack of income data. Given the cross-sectional nature of our data, we are unable to make causal inferences.

Nonetheless, the limitations were offset by several strengths. The study is the first to estimate the prevalence of overweight/obesity and EDs/DEBs in a nationally representative sample of over 14,000 young adults, which allowed us to detect associations in subsets such as by sex, race/ethnicity, or sexual orientation.

\section{CONCLUSION}

Over $30 \%$ of female and $15 \%$ of male young adults at a weight status classified as overweight/obese reported an ED or DEB. Young adults at a weight status classified as overweight/obese were more likely than those at a weight status classified as underweight/normal weight to report DEBs. Females, sexual minorities, Asian/Pacific Islanders, those with less educational attainment, and those with higher weight status had higher odds of DEBs and may benefit from targeted interventions for the co-occurrence of overweight/obesity and EDs/DEBs. Future research may identify longitudinal predictors and longterm outcomes of the coexistence of overweight/obesity and EDs/DEBs in young adulthood.

Acknowledgments: Thanks to Nicole Capdarest-Arest for help with literature searches. This research uses data from Add Health, a program project directed by Kathleen Mullan Harris and designed by J. Richard Udry, Peter S. Bearman, and Kathleen Mullan Harris at the
University of North Carolina at Chapel Hill, and funded by grant PO1HD31921 from the Eunice Kennedy Shriver National Institute of Child Health and Human Development, with cooperative funding from 23 other federal agencies and foundations. Special acknowledgment is due Ronald R. Rindfuss and Barbara Entwisle for assistance in the original design. Information on how to obtain the Add Health data files is available on the Add Health website (http://www.cpc.unc. edu/addhealth). No direct support was received from grant PO1HD31921 for this analysis.

Corresponding Author: Jason M. Nagata, MD, MSc; Division of Adolescent and Young Adult Medicine, University of California, San Francisco, CA, USA (e-mail: jasonmnagata@gmail.com).

Funding Information Jason Nagata is a Fellow in the Pediatric Scientist Development Program (K12HD000850-33). This project was supported by grants from the American Academy of Pediatrics (AAP), the American Pediatric Society (APS), and the Norman Schlossberger Research Fund from the University of California, San Francisco. A.K.G. was supported by NIH 5RO1HD082166-02. S.B.M was supported by K23 MH115184.

\section{Compliance with Ethical Standards:}

The University of North Carolina Institutional Review Board approved all Add Health study procedures, and the University of California, San Francisco Institutional Review Board deemed this specific project exempt. Written informed consent was obtained from each subject.

Conflict of Interest: The authors declare that they do not have a conflict of interest.

\section{REFERENCES}

1. Ogden CL, Carroll MD, Fryar CD, Flegal KM. Prevalence of obesity among adults and youth: United states, 2011-2014. NCHS Data Brief. 2015;(219): 1-8.

2. Ackard DM, Neumark-Sztainer D, Story M, Perry C. Overeating among adolescents: prevalence and associations with weight-related characteristics and psychological health. Pediatrics 2003;111(1):67-74.

3. Ogden CL, Carroll MD, Kit BK, Flegal KM. Prevalence of childhood and adult obesity in the united states, 2011-2012. JAMA 2014;311(8):806-14.

4. Hudson JI, Hiripi E, Pope HG, Jr., Kessler RC. The prevalence and correlates of eating disorders in the National Comorbidity Survey Replication. 2007;61:348-58.

5. Favaro A, Ferrara S, Santonastaso $\mathbf{P}$. The spectrum of eating disorders in young women: a prevalence study in a general population sample. Psychosom Med 2003;65(4):701-8.

6. American Psychiatric Association. Diagnostic and statistical manual of mental disorders. 5th Ed. Washington, D.C.: American Psychiatric Association; 2013.

7. Striegel-Moore RH, Bulik CM. Risk factors for eating disorders. Am Psychol 2007;62(3):181-98.

8. McKnight Investigators. Risk factors for the onset of eating disorders in adolescent girls: rsesults of the McKnight longitudinal risk factor study. Am J Psychiatry 2003;160(2):248-54.

9. Neumark-Sztainer D, Wall M, Larson NI, Eisenberg ME, Loth K. Dieting and disordered eating behaviors from adolescence to young adulthood: findings from a 10-year longitudinal study. J Am Diet Assoc 2011;111(7):1004-11.

10. French SA, Story M, Downes B, Resnick MD, Blum RW. Frequent dieting among adolescents: psychosocial and health behavior correlates. Am J Public Health 1995;85(5):695-701.

11. Neumark-Sztainer D, Wall M, Guo J, Story M, Haines J, Eisenberg M. Obesity, disordered eating, and eating disorders in a longitudinal study of adolescents: how do dieters fare 5 years later? J Am Diet Assoc 2006; 106(4):559-68.

12. Loth K, Wall M, Larson N, Neumark-Sztainer D. Disordered eating and psychological well-being in overweight and nonoverweight adolescents: secular trends from 1999 to 2010. Int J Eat Disord. 2015;48(3):323-7.

13. Neumark-Sztainer D, Wall $\mathbf{M}$, Story $\mathbf{M}$, Standish AR. Dieting and unhealthy weight control behaviors during adolescence: associations with 10-year changes in body mass index. J Adolesc Health 2012;50(1):80-6. 
14. Neumark-Sztainer DR, Wall MM, Haines JI, Story MT, Sherwood NE, van den Berg PA. Shared risk and protective factors for overweight and disordered eating in adolescents. Am J Prev Med 2007;33(5):359-69.

15. Berkowitz R, Stunkard AJ, Stalling VA. Binge-eating disorder in obese adolescent girls. Ann N Y Acad Sci 1993;699(1):200-6.

16. Isnard $\mathbf{P}$, Michel $\mathbf{G}$, Frelut $\mathbf{M}$, et al. Binge eating and psychopathology in severely obese adolescents. Int J Eat Disord. 2003;34(2):235-43.

17. Liechty JM, Lee MJ. Longitudinal predictors of dieting and disordered eating among young adults in the U.S. Int J Eat Disord 2013;46(8):790-800.

18. Stephen EM, Rose JS, Kenney L, Rosselli-Navarra F, Weissman RS Prevalence and correlates of unhealthy weight control behaviors: findings from the national longitudinal study of adolescent health. J Eat Disord. 2014;2:16,2974-2-16. eCollection 2014

19. Stroud C, Walker LR, Davis M, Irwin CE, Jr. Investing in the health and well-being of young adults. J Adolesc Health 2015;56(2):127-9.

20. Croll J, Neumark-Sztainer D, Story M, Ireland M. Prevalence and risk and protective factors related to disordered eating behaviors among adolescents: relationship to gender and ethnicity. J Adolesc Health 2002;31(2):166-75.

21. Murray SB, Accurso EC, Griffiths S, Nagata JM. Boys, biceps, and bradycardia: the hidden dangers of muscularity-oriented disordered eating. J Adolesc Health 2018;62(3):352-5.

22. Murray SB, Nagata JM, Griffiths S, et al. The enigma of male eating disorders: a critical review and synthesis. Clin Psychol Rev 2017;57:1-11.

23. Robinson TN, Killen JD, Litt IF, et al. Ethnicity and body dissatisfaction: are Hispanic and Asian girls at increased risk for eating disorders? J Adolesc Health 1996;19(6):384-93.

24. Lee-Winn A, Mendelson T, Mojtabai R. Racial/ethnic disparities in binge eating: disorder prevalence, symptom presentation, and helpseeking among Asian Americans and non-Latino Whites. Am J Public Health 2014; 104(7):1263-5.

25. Strong SM, Williamson DA, Netemeyer RG, Geer JH. Eating disorder symptoms and concerns about body differ as a function of gender and sexual orientation. J Soc Clin Psychol 2000;19(2):240-55.

26. Laska MN, VanKim NA, Erickson DJ, Lust K, Eisenberg ME, Rosser BR. Disparities in weight and weight behaviors by sexual orientation in college students. Am J Public Health 2015;105(1):111-21.

27. Tabler J, Utz RL. The influence of adolescent eating disorders or disordered eating behaviors on socioeconomic achievement in early adulthood. Int J Eat Disord. 2015;48(6):622-32.

28. Harris KM, Halpern CT, Witsel E, et al. The national longitudinal study of adolescent to adult health: research design. Available at: http://www. cpc.unc.edu/projects/addhealth/design/researchdesign_3618_regular. pdf. Accessed 24 May 2018

29. Fairburn CG, Beglin S. Eating Disorder Examination Questionnaire. In: Fairburn CG, editor. Cognitive Behavior Therapy and Eating Disorders. New York: Guilford Press; 2008. p. 309-313.

30. Sallis JF, Buono MJ, Roby JJ, Micale FG, Nelson JA. Seven-day recall and other physical activity self-reports in children and adolescents. Med Sci Sports Exerc 1993;25(1):99-108.

31. Wang EA, Pletcher M, Lin F, et al. Incarceration, incident hypertension, and access to health care: findings from the Coronary Artery Risk Development in Young Adults (CARDIA) study. Arch Intern Med 2009; 169(7):687-93.

32. Hudson DL, Puterman E, Bibbins-Domingo $\mathbf{K}$, Matthews KA Adler NE. Race, life course socioeconomic position, racial discrimination, depressive symptoms and self-rated health. Soc Sci Med 2013;97:7-14.

33. Araya R, Lewis G, Rojas G, Fritsch R. Education and income: which is more important for mental health? J Epidemiol Community Health 2003;57(7):501-5.

34. Winkleby MA, Jatulis DE, Frank E, Fortmann SP. Socioeconomic status and health: how education, income, and occupation contribute to risk factors for cardiovascular disease. Am $J$ Public Health 1992;82(6):816-20.

35. Geyer S, Hemstrom O, Peter R, Vagero D. Education, income, and occupational class cannot be used interchangeably in social epidemiology. Empirical evidence against a common practice. J Epidemiol Community Health 2006;60(9):804-10.

36. Hay P, Girosi F, Mond J. Prevalence and sociodemographic correlates of DSM-5 eating disorders in the Australian population. J Eat Disord. 2015;3:19,015-0056-0. eCollection 2015.

37. Centers for Disease Control and Prevention (CDC). Defining adult overweight and obesity. Available at: https://www.cdc.gov/obesity/ adult/defining.html. Accessed 24 May 2018.

38. Harris KM. The Add Health study: design and accomplishments. Carolina Population Center, University of North Carolina at Chapel Hill; 2013.

39. Chen P. Appropriate analysis in add health: correcting for design effects \& selecting weights. Carolina Population Center, University of North Carolina at Chapel Hill; 2014.

40. Hildebrandt T, Langenbucher J, Schlundt DG. Muscularity concerns among men: development of attitudinal and perceptual measures. Body Image 2004; 1(2):169-81.

41. Murray SB, Griffiths S, Nagata JM. Community-based eating disorder research in males: a call to action. J Adolesc Health. 2018;62(6):649-650.

42. Nagata JM, Golden NH, Peebles R, et al. Assessment of sex differences in body composition among adolescents with anorexia nervosa. J Adolesc Health 2017;60(4):455-9.

43. Nagata JM, Golden NH, Peebles R, et al. Assessment of sex differences in bone deficits among adolescents with anorexia nervosa. Int $\mathrm{J}$ Eat Disord. 2017;50(4):352-358.

44. Nagata JM, Golden NH, Leonard MB, Copelovitch L, Denburg MR. Assessment of sex differences in fracture risk among patients with anorexia nervosa: a population-based cohort study using the health improvement network. J Bone Miner Res 2017;32(5):1082-1089.

45. Nagata JM, Carlson JL, Kao JM, Golden NH, Murray SB, Peebles R. Characterization and correlates of exercise among adolescents with anorexia nervosa and bulimia nervosa. Int $J$ Eat Disord. 2017;50(12):1394-403.

46. Murray SB, Griffiths S, Mond JM, Kean J, Blashill AJ. Anabolic steroid use and body image psychopathology in men: delineating between appearance- versus performance-driven motivations. Drug Alcohol Depend 2016;165: 198-202.

47. Taylor CB, Sharpe T, Shisslak C, et al. Factors associated with weight concerns in adolescent girls. Int J Eat Disord. 1998;24(1):31-42.

48. American Psychiatric Association. Diagnostic and statistical manual of mental disorders. 4th Edition ed. Washington, D.C.: American Psychiatric Association; 1990.

49. Golden NH, Schneider M, Wood C, Committee on Nutrition, Committee on Adolescence, Section on Obesity. Preventing obesity and eating disorders in adolescents. Pediatrics. 2016;138(3):https://doi.org/10. 1542/peds.2016-1649. 